\title{
Association of maternal physical status and pregnancy outcome
}

\author{
Namrata Tiwari ${ }^{1 *}$, Vinay Mishra ${ }^{2}$ \\ ${ }^{1}$ Department of Obstetrics and Gynecology, KEM Hospital, Parel, Mumbai, Maharashtra, India
}

${ }^{2}$ Department of Paediatrics, Cuddles and Cure, Mulund, Mumbai, Maharashtra, India

Received: 28 November 2019

Revised: 27 December 2019

Accepted: 02 January 2020

\section{*Correspondence:}

Dr. Namrata Tiwari,

E-mail: dr.namrata28@gmail.com

Copyright: ( $\odot$ the author(s), publisher and licensee Medip Academy. This is an open-access article distributed under the terms of the Creative Commons Attribution Non-Commercial License, which permits unrestricted non-commercial use, distribution, and reproduction in any medium, provided the original work is properly cited.

\begin{abstract}
Background: Lots of research both in India and abroad studying the effect of maternal physical markers on their infant's birth weight is going on. The present study has been planned to evaluate the effects of maternal physical markers on their infant's anthropometry and cord blood haemoglobin.

Methods: Maternal background information, height, last known pre-pregnancy weight, gestational age and number of children was obtained and recorded in case proforma. 100 post-partum women and their newborns were studied. The study was carried in a post-natal ward of a tertiary care hospital. Maternal and neonatal data were recorded.

Results: Maternal physical status (pre-pregnancy weight, height and BMI) significantly influences the pregnancy outcome (neonatal parameters) of the baby.

Conclusions: There should be emphasis on improvement in nutrition of the girl child to improve the health of the upcoming generations. Maternal body mass index needs to be optimized to reduce perinatal complications to both mother and the baby.
\end{abstract}

Keywords: Anthropometry, Body mass index, Height, Newborn, Pregnancy outcome, Weight

\section{INTRODUCTION}

The growth of a new-born is affected by various prenatal, perinatal and post-natal factors. It is well known that optimum physical features pre- pregnancy affects health of mother and the child in long run. Thus, maternal nutrition plays an important role in life long health of baby. Therefore, the knowledge of maternal nutrition and foetal growth is crucial. Assessment of maternal nutrition depends upon maternal physical markers like prepregnancy weight, height, BMI etc.

Pregnancy outcome depends on birth weight, new-born physical parameters and cord blood haemoglobin. Poor maternal nutrition leads to low birth weight (LBW, birth weight $<2500 \mathrm{~g}$ ) related to high morbidity and mortalit. ${ }^{1}$ Despite advanced medical practices in the field of reproduction and child health, the infant mortality rate which is widely taken as an indicator of population's health status remains high. The two leading causes of neonatal deaths are low birth weight and prematurity in which maternal anthropometry (height, weight BMI, etc.) plays an important role.

Objective of this study was to study the effect of maternal physical markers on the neonatal parameters and cord blood haemoglobin concentration of their new-borns.

To study the effect of physical maternal markers (viz. weight, height, body mass index (BMI) and on pregnancy outcome determined by following neonatal parameters.

- Anthropometric parameters of their newborn

- Cord blood haemoglobin of their new born. 


\section{METHODS}

Study area: This was an observational study done in the post-natal ward of our hospital. Before the start of our study an ethics committee clearance was obtained.

Post-delivery informed consent of women willing for the study was obtained. All women and their new-borns fulfilling the inclusion criteria were enrolled. A total of 100 mother-newborn pairs were selected from July 2011 to June 2012.

\section{Inclusion criteria}

- $\quad$ Pre-term and term live birth neonate- mother pairs whose hospital stay exceeded one day

- Newborns born by vaginal and caesarean delivery.

\section{Exclusion criteria}

- Unregistered mothers

- Mothers with any maternal disorder like diabetes mellitus, pregnancy induced hypertension, connective tissue disorder

- Multiple pregnancy

- Newborns with congenital malformations.

Maternal background information, height, last known pre-pregnancy weight, gestational age and number of children was obtained and recorded in case proforma.

Last known pre-pregnancy weight was recorded. Gestational age was calculated from Naegele's formula. The weighing machine was standardized frequently. The weight was recorded to the nearest $50 \mathrm{gm}$.

Height was measured keeping the women standing on level ground, without footwear, against a wall, by using measuring tape to the nearest of $0.5 \mathrm{~cm}$. Pre-pregnancy
Body mass index (BMI) was calculated using formula weight $(\mathrm{kg}) /$ height $\left(\mathrm{m}^{2}\right)$.

New-born weights were measured using electronic weighing scale. Length, head circumference and chest circumference were measured within 48 hours after birth using non-stretchable measuring tape to the nearest of 0.5 $\mathrm{cm}$. Ponderal index of the new-borns was calculated using formula weight (gms)/length $\left(\mathrm{cm}^{3}\right)$.

\section{Statistical analysis}

The data obtained was analysed using SPSS 20 software. The two groups were compared using one-way analysis of variance. For more than two groups comparisons posthoc analysis was done using Tukey test. Pearson correlation coefficient was used. P-value less than 0.05 was considered significant.

\section{RESULTS}

In the present study, the mean pre-pregnancy weight and height were $58.04 \mathrm{~kg}$ and $158.86 \mathrm{~cm}$ with a body mass index (BMI) of the study population mothers was 23.09. (Table 1).

Table 1: Anthropometric features of mothers.

\begin{tabular}{|llll|}
\hline Maternal characteristics & Mean & Median & SD \\
\hline $\begin{array}{l}\text { Maternal pre-pregnancy } \\
\text { weight (kg) }\end{array}$ & 58.04 & 59.00 & 8.785 \\
\hline Maternal height (cms) & 158.86 & 159.00 & 5.002 \\
\hline Body mass index (BMI) & 23.09 & 23.23 & 3.189 \\
\hline
\end{tabular}

The means of the maternal characteristics of the studied population as described in Table 1 are as follows. The mean pre-pregnancy weight and height were, $58.04 \mathrm{~kg}$ and $158.86 \mathrm{~cm}$ with a body mass index (BMI) of the study population mothers was 23.09 .

Table 2: Influence of pre-pregnancy weight on length of the baby $(n=100)$.

\begin{tabular}{|c|c|c|c|}
\hline \multirow{2}{*}{ Pre-pregnancy weight (kg) } & \multicolumn{3}{|c|}{ Length (cm) } \\
\hline & $\mathbf{N}$ & Mean & SD \\
\hline Less than 40 & 5 & 46.20 & 0.45 \\
\hline $41-50$ & 15 & 49.67 & 1.99 \\
\hline $51-60$ & 40 & 50.38 & 2.81 \\
\hline $61-70$ & 33 & 51.09 & 1.97 \\
\hline More than 70 & 7 & 49.57 & 1.40 \\
\hline
\end{tabular}

One-way analysis of variance followed by post-hoc analysis results: Mean length in pre-pregnancy weight categories 41-50, 51-60 and 61-70 are significantly higher than that of less than $40 \mathrm{~kg}$ category $(\mathrm{P}<0.05)$. No statistically significant difference seen among any of the categories (Table 2).
There is statistically significant $(\mathrm{P}=0.031)^{*}$ positive correlation between mothers pre-pregnancy weight and length of the new-born (Table 3).

There is statistically significant $(\mathrm{P}=0.002)^{*}$ positive correlation between mother's height and head circumference of the new born (Table 4). 
Table 3: Pearson correlation coefficients (P-values in brackets) between maternal pre-pregnancy weight and neonatal parameters (stature and cord blood haemoglobin).

\begin{tabular}{|lllllll|}
\hline Parameters & $\begin{array}{l}\text { Birth } \\
\text { weight }(\mathrm{kg})\end{array}$ & $\begin{array}{l}\text { Length } \\
(\mathrm{cm})\end{array}$ & $\begin{array}{l}\mathrm{HC} \\
(\mathrm{cm})\end{array}$ & $\begin{array}{l}\mathrm{CC} \\
(\mathbf{c m})\end{array}$ & $\begin{array}{l}\text { Ponderal } \\
\text { Index }\end{array}$ & $\begin{array}{l}\text { Cord blood Hb } \\
(\mathrm{gm} \%)\end{array}$ \\
\hline $\begin{array}{l}\text { Mothers pre-pregnancy } \\
\text { weight }(\mathrm{kg})\end{array}$ & 0.052 & 0.216 & 0.042 & 0.005 & -0.156 & 0.063 \\
\hline
\end{tabular}

*Statistically significant values.

Table 4: Pearson correlation coefficients (P-values in brackets) between maternal height and neonatal parameters (anthropometry and cord blood haemoglobin).

\begin{tabular}{|c|c|c|c|c|c|c|}
\hline Parameters & $\begin{array}{l}\text { Birth weight } \\
\text { (kg) }\end{array}$ & $\begin{array}{l}\text { Length } \\
\text { (cm) }\end{array}$ & $\begin{array}{l}\mathrm{HC} \\
(\mathrm{cm})\end{array}$ & $\begin{array}{l}\mathrm{CC} \\
(\mathrm{cm})\end{array}$ & $\begin{array}{l}\text { Ponderal } \\
\text { index }\end{array}$ & $\begin{array}{l}\text { Cord blood Hb } \\
(\mathrm{gm} \%)\end{array}$ \\
\hline Mothers height $(\mathrm{cm})$ & $\begin{array}{l}0.130 \\
(0.196)\end{array}$ & $\begin{array}{l}0.163 \\
(0.106)\end{array}$ & $\begin{array}{l}0.305 \\
(0.002)^{*}\end{array}$ & $\begin{array}{l}0.168 \\
(0.095)\end{array}$ & $\begin{array}{l}-0.068 \\
(0.503)\end{array}$ & $\begin{array}{l}0.019 \\
(0.849)\end{array}$ \\
\hline
\end{tabular}

*Statistically significant values.

\section{DISCUSSION}

The indicators of nutritional status of newborn are physical parameters and cord blood haemoglobin and that of mother are height, weight and BMI.

Anthropometry has been since long used as a marker of well-being of a newborn infant. Birth weight has been the most common marker used to assess the intra-uterine growth since it is easier to measure and modern balances can measure weight up to nearest five grams. Also, other parameters like length measured with the help of an infantometer, head and chest circumference measured using a non-stretchable measuring tape are widely used to assess the growth and development of a newborn during the intra-uterine life. Birth weight is an important marker of child's lifespan. Birth weight not only implies the intra-uterine growth but it also has implications on adult life.

It is evident that taller mothers ( $>165 \mathrm{~cm}$ ) gave birth to heavier newborns as compared to short statured mothers $(<150 \mathrm{~cm})$, however this was not significant statistically. Other research workers like Elshibly and Schmalisch found that maternal height was the most important maternal parameters influencing birth weight and the risk for $\mathrm{LBW}{ }^{3}$

Elshibly and Schmalisch reported preterm birth rate of $5.7 \%$ in their study. ${ }^{3}$ The WHO report puts the worldwide incidence of preterm births (<37 weeks) at $11.1 \% .^{4}$ However our study, though with a smaller sample size showed preterm birth rate of $7 \%$. This was due to the better government services and nutrition offered to the mothers.

In our study, the incidence of low birth weight is $22 \%$. In developing countries like ours, this is because of poor in utero growth of foetus. ${ }^{5}$
Our results pointed out that as the pre-pregnancy weight increased there was a corresponding increase in the mean birth weight and this relationship was statistically significant (Table 4). Many research workers have reported an increase in the mean birth weight as the prepregnancy weight increased. ${ }^{6}$ This emphasizes the role of adequate nutrition prior to pregnancy and preparation for the demands of the periods of increased metabolism during pregnancy.

The present study also revealed statistically significant ( $P$ $=0.002$ ) positive correlation between mother's height and head circumference of the newborn (Table 4). This effect was not studied before. Thus, long term nutrition of the female, reflecting in the stature of the mother has an effect on the fetal development.

There was no statistically significant correlation between mother's height and weight and cord blood $\mathrm{Hb}$.

Undernourished girls later turn into undernourished lady who give birth to a new generation of undernourished kids. It affects country's economy . Thus, there is a need to improve the health of adolescent girls in developing countries. ${ }^{7}$

\section{CONCLUSION}

Widespread poor maternal nutrition leads to low birth weight neonates. The mothers give birth to babies who are not only low birth weight but also have reduced anthropometric markers like length, head circumference, chest circumference and Ponderal index.

To conclude, pre-pregnancy weight, height and BMI has a very significant impact on the pregnancy outcome measured by neonatal anthropometric parameters. The better pregnancy outcome will decrease the overall infant morbidity and mortality. 
Funding: No funding sources

Conflict of interest: None declared

Ethical approval: The study was approved by the

Institutional Ethics Committee

\section{REFERENCES}

1. Winikoff B, Debrovner $\mathrm{CH}$. Anthropometric determinants of birth weight. J Obstet Gynaecol. 1981;58:678-84.

2. Singhal A, Wells J, Cole TJ, Fewtrell M, Lucas A. Programming of lean body mass: a link between birth weight, obesity, and cardiovascular disease? Am J Clin Nutr. 2003;77(3):726-30.

3. Elshibly EM, Schmalisch G. The effect of maternal anthropometric characteristics and social factors on gestational age and birth weight in Sudanese newborn infants. BMC Pub Health. 2008;8:244.

4. Chang HH, Larson J, Blencowe H, Spong CY, Howson CP. Preventing preterm births: analysis of trends and potential reductions with interventions in
39 countries with very high human development index. The Lancet. 2013;381(9862):223-34.

5. Ganesh Kumar S, Kumar HN, Jayaram S, Kotian MS. Determinants of low birth weight: a case control study in a district hospital in Karnataka. Indian $\mathbf{J}$ Pediatr. 2010;77:87-9.

6. Rao PRS, Prakash KP, Nair NS. Influence of prepregnancy weight, maternal height and weight gain during pregnancy on birth weight. Bahrain Med Bull. 2001;23(1):22-6.

7. Gogoi G, Ahmed FU. Effect of maternal nutritional status on the birth weight among women of tea tribe in Dibrugarh district. Indian $\mathbf{J}$ Comm Med. 2007;32:120-2.

Cite this article as: Tiwari N, Mishra V. Association of maternal physical status and pregnancy outcome. Int J Reprod Contracept Obstet Gynecol 2020;9:7014. 